\title{
Mathematical Modelling and Experimental Validation of Solar Assisted Heat Pump System
}

\author{
Mahbubul Muttakin ${ }^{1}$, Zakaria Mohd. Amin ${ }^{2}$ \\ ${ }^{I}$ (Dept. of Mech. Engg, National University of Singapore, Singapore) \\ ${ }^{2}$ (Research Fellow, Queensland University of Technology, Australia)
}

\begin{abstract}
Singapore is located at the equator, with abundant supply of solar radiation, relatively high ambient temperature and relative humidity throughout the year. The meteorological conditions of Singapore are favourable for efficient operation of solar energy based systems. Solar assisted heat pump systems are built on the roof-top of National University of Singapore's Faculty of Engineering. The objectives of this study include the design and performance evaluation of a solar assisted heat-pump system for water desalination, water heating and drying of clothes. Using MATLAB programming language, a 2-dimensional simulation model has been developed to conduct parametric studies on the system. The system shows good prospect to be implemented in both industrial and residential applications and would give new opportunities in replacing conventional energy sources with green renewable energy.
\end{abstract}

Keywords: Desalination, Heat pump, Simulation, Solar thermal.

\section{Introduction}

In view of rising global energy needs and energy crisis due to depletion of conventional energy resources, extensive research and development programs are conducted over the decades in order to discover other possible energy resources to replace conventional energy sources. In conjunction with increasing awareness of the negative environmental impacts caused by the conventional energy sources, scientists and engineers are also looking into alternative methods to harness energy from green renewable energy sources; i.e. solar, wave, wind, bio-fuel energy resources. Solar energy from the sun is the cleanest, non-depleting, most abundant renewable energy source available on Earth, which makes solar systems more cost-effective for industrial and residential thermal applications [1].

In addition to global energy crisis, water shortage is also another critical problem faced by many nations worldwide. Although $70.8 \%$ of the earth surface is covered by water, only $3 \%$ of the water masses are freshwater [2]. Despite of scarcity of freshwater on Earth, only $0.5 \%$ of freshwater supplies are available in useable form. Water is an essential element for life, where all living being on earth depends on water for survival [3]. World Health Organization's (WHO) statistic shows that each day, approximately 3,900 children die because of lack of fresh sanitized water [4].

In Singapore, the available reservoirs, including the newly commissioned Marina Barrage are unable to support the daily needs of water. Currently, a large portion of the daily water demand in Singapore is met by purchasing raw untreated water from the neighbouring nation, Malaysia. In 1998, the Singapore Water Reclamation Study was initiated by the Public Utilities Board and Ministry of the Environment and Water Resources. Using reverse osmosis technique, freshwater was produced from sewage water and is branded as NEWater. Singapore being an island-nation surrounded by the sea, there is great potential in producing unlimited supply of freshwater through seawater desalination. In global context, nations worldwide can also make use of the desalination systems to increase freshwater supply and become less dependent on the already scarce freshwater sources.

\subsection{Sea-water desalination}

Water desalination has been present and occurring naturally in the environment, through the water cycle. In today's studies, desalination can be categorized into 2 different processes, mainly thermal processes and membrane processes. In thermal processes, we have multi-stage flash distillation (MSF), multi-effect distillation (MED), solar evaporation, freezing and vapour compression distillation (VC). Reverse osmosis (RO) and electro-dialysis (ED) fall under membrane desalination processes.

\subsubsection{Multi-stage flash desalination (MSF)}

Multi-stage flash desalinations operate on the principle of flash evaporation. In MSF, seawater is evaporated through the reduction of pressure; in such a case, the saturation temperature of water becomes less than that at atmospheric pressure. In large MSF plants, seawater or brine water usually undergoes 19 to 28 stages of flash chambers; each chamber operates at a pressure lower than the corresponding saturation 
temperature of the inlet seawater. Before feeding seawater into the MSF chambers, seawater is preheated to the operating temperature of around $90-120^{\circ} \mathrm{C}$ by externally supplied low pressure steam. Economies of conventional MSF are achieved through regenerative heating, where heat released during flashing of seawater, and latent heat released by condensing vapour of each stage gradually increases the temperature of incoming seawater, thereby reducing external thermal energy input during pre-heating [5].

\subsubsection{Multi-effect desalination (MED)}

Multiple-effect distillation (MED) process is the oldest desalination method. MED process operates on the principle of reducing the ambient pressure in various effects, allowing seawater feed to undergo multiple boiling without supplying additional heat after the first effect [5]. Compared with MSF, seawaters are mainly evaporated through heat supplied from the condenser coil, thus working on the same principle of lowering saturation temperature of water with decreasing pressure.

\subsection{Solar Assisted Heat Pump System (SAHPS)}

Different forms of heat pump systems have been in use for decades. Over the last decade, a number of researches and studies have been conducted on the design, modelling and testing of solar-assisted heat pump (SAHP) systems.

\subsubsection{Solar assisted heat pump for water heating}

Conventionally, water heating in the residential sector is conducted via electrical heating or boiling with natural gases, with a small percentage of private household engaging thermosyphon solar water heating system. Thermosyphon solar water heating has low maintenance and does not involve input of compressor work, but its heating capacity is relatively limited by solar radiation.

Chaturvedi et al. [6] studied the variable capacity direct expansion SAHPS for domestic hot water application. The experimental result shows that as ambient temperature increases, coefficient of performance (COP) for the system can be increased significantly by reducing the compressor frequency.

Hawlader et al. [7] designed, fabricated and tested a SAHP dryer and water heater system. They investigated the performance of the system under Singapore's meteorological conditions.

Huang and Chyng [8] investigated the characteristics of an integral-type solar-assisted heat pump (ISAHP), which integrated a Rankine refrigeration cycle and a thermosyphon loop. A performance model was derived for the ISAHP system, and the COP values of the system are found to be in the range of 2.5 to 3.7, depending on the water temperatures.

\subsubsection{Solar assisted heat pump for drying and space heating}

Best et al [1994] designed and conducted studies on his prototype solar assisted heat pump rice drying chamber. A horizontal single glazed flat plate collector was installed at the chamber where air flowed on both side of the black painted absorber. Operating on one pass mode with solar heating, the consumed energy was $166.8 \mathrm{~kJ} / \mathrm{kg}$ of dried rice [9].

Chaturvedi et al [10] performed studies on thermodynamic analysis of two-phase flow in solar collectors with application to a direct-expansion SAHP. Studies showed that changes in the mass-flow rate and absorbed solar heat flux have significant effects on the collector tube length and refrigerant heat transfer coefficient. It was also observed that increase in vapour quality of refrigerant mixture is gradual over the major length of the tube, with rapid increase of quality occurring at the end of the tube. The method used in Chaturvedi's studies can easily be extended to incorporate matching between collector size and compressor heat-pumping capacity.

Yumrutas and Koska [11] designed, constructed and investigated an experimental SAHP system for space heating. In addition, a daily energy storage tank was installed to evaluate its performance. Results of the studies showed that the COP of the system was about 2.5 for a lower storage temperature and 3.5 for a higher storage temperature.

\section{Experimental Setup}

The experimental setup is built and located at the rooftop of Block EA of the National University of Singapore. Experiments on the system are conducted under Singapore's meteorological conditions, while the system performance is analyzed and evaluated for different operating conditions. 


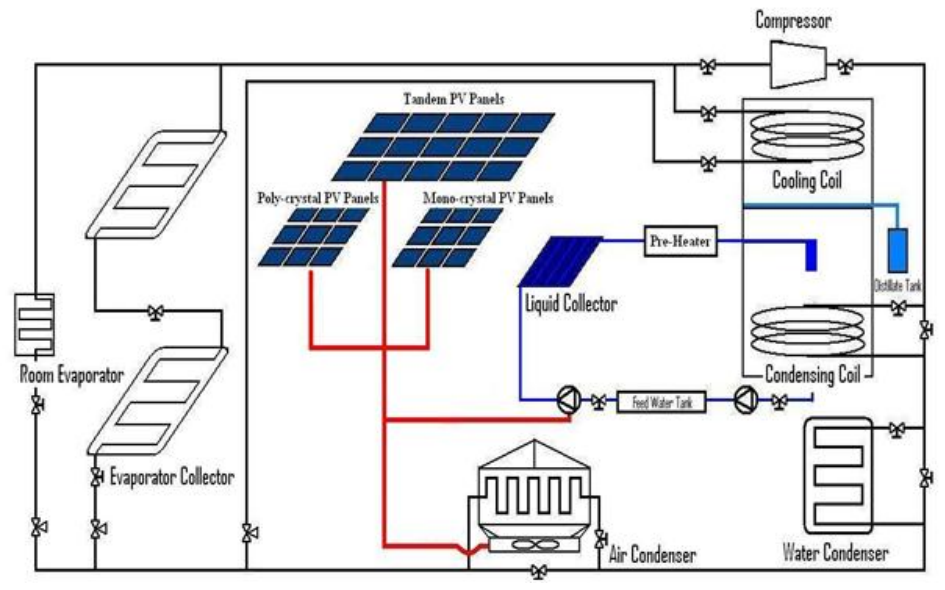

Figure 2.1 Schematic Diagram of SAHP system

The system consist of two parts, a solar-assisted heat pump system, with refrigerant R143a as the working fluid, and a desalination part, which preheats the feed water and distillates water. The system's schematic diagram is illustrated in Fig. 2.1.

\subsection{Working principles \\ 2.1.1 Working principle of SAHP}

The SAHP consists of a hermetic type reciprocating compressor, followed by the condensing coil in lower portion of desalination chamber, water-cooled condenser, air-cooled condenser, expansion valves and lastly the evaporator components;- evaporator-collector, room evaporator and cooling coil in upper portion of desalination chamber. The evaporator components are connected in parallel to each other, while the condenser components are connected in series, with by-pass valves for each.

In the compressor, saturated refrigerant vapour at a lower pressure enters the inlet and is compressed to a high pressure superheated vapour. The superheated vapour first enters the condenser coil in the desalination chamber, where it releases sensible and latent heat, and evaporates saturated feed water in the desalination chamber. Subsequently, to ensure total condensation of refrigerant, the refrigerant flows through the coil immersed in water of the condenser tank and then passes through the air-cooled condenser. Latent heat released from the condensation of refrigerant vapour is received by water and air in the water-cooled condenser and aircooled condenser respectively. This received heat in the water-cooled condenser and air-cooled condenser are utilized in thermal application of water heating and clothes drying respectively, which are usually dumped into environment as waste heat by the conventional heat pump system.

The sub-cooled liquid refrigerant from the condensers is then split into three separate branches. Each branch leads the refrigerant to separate evaporator components. Refrigerant mass flow rate in each branch is regulated by the thermostatic expansion valve before entering the evaporator components. In the evaporatorcollector, collector plate gains solar energy from solar radiation. Energy gained by the collector plates is then transferred to vaporize the two-phase refrigerant in the serpentine tubes. In the room evaporator, refrigerant vaporizes by receiving thermal energy from room air, while the room air is cooled by releasing heat to the cold refrigerant flowing in finned tubes. Lastly, refrigerant flowing through the cooling coil in the desalination chamber vaporizes after gaining latent energy released during film condensation of water vapour on the horizontal cooling coil. The mass flow rate of refrigerant in each evaporator is regulated to ensure that the refrigerant exits each evaporator in saturated or superheated vapour state. The three streams of refrigerant vapour are then mixed together before entering the compressor inlet, where the whole refrigerant vapourcompression cycle continues.

\subsubsection{Working principle of desalination}

The desalination system consists of a commercial solar collector, electrical heater, desalination chamber, vacuum pump, distillate tank, positive displacement pumps and a feed water tank. The pumps are powered by Photovoltaic (PV) panels during sunny operating conditions and external grid during cloudy/night time operations. Feed water is pumped through the solar collector to be preheated by solar energy. If the temperature of the feed water exiting the solar collector is below the desired temperature, the electrical heater positioned after the solar collector provides auxiliary heating to maintain the temperature of feed water at the required temperature. In practice, the temperature of feed water before entering the desalination should not be below $70^{\circ} \mathrm{C}$. After passing through the electrical heater, the water enters the desalination chamber which is evacuated to a pressure of 0.12 bar. At such a low pressure, the corresponding saturation temperature of water 
becomes only $50^{\circ} \mathrm{C}$. Upon entering the desalination chamber, the water undergoes thermodynamic flashing; as the saturation temperature of water in the chamber is lower than the inlet temperature of water. The remaining part of the water that does not evaporate during flashing falls onto the bottom of the desalination chamber, where it is further heated up and evaporated by the condensing coil of the heat pump system. Vapours produced from flashing and evaporation rise to the top of the chamber, where they are condensed on the cooling coil of the heat pump. The phenomenon of condensed water on the cooling coil is known as film condensation. The condensed water accumulates into large water droplets and falls onto the collection tray below the cooling coil. The distilled water then flows and is stored in a distillate tank outside the desalination chamber. Concentrated brine water accumulated at the bottom of the chamber is removed by a positive displacement pump and fed into the feed water tank.

\subsubsection{Working principle of clothes dryer}

The clothes dryer consists of a blower, air cooled condenser, drying chamber and a fan duct system. The blower draws ambient air into the air cooled condenser. Air flows over the finned exterior coils in the condenser, where heat transfer between air and refrigerant takes place. The air gains thermal energy from the latent heat released by the condensing refrigerant and the hot air is then channelled into the drying chamber. The drying materials used in this study are wet towels and wet clothes. The drying materials are hung vertically, with hot air rising and flowing from the bottom of the chamber. This arranged design allows optimum exposure of drying materials to the hot air. Humid air is then vented out to the atmosphere after drying.

\subsection{Components of the system}

All the components are designed to meet the desired load of the system. Two $1.5 \mathrm{~m}$ by $1 \mathrm{~m}$ unglazed collector plates are connected in series in the present study. The collector plates are made of copper, with $2 \mathrm{~mm}$ thickness, and painted black for better absorptive and emissive coefficients. Copper tubes, having external and internal diameter of $9.5 \mathrm{~mm}$ and $8.5 \mathrm{~mm}$ respectively, are soldered to the downward facing side of the collector plate.

A $2 \mathrm{~m}$ by $1 \mathrm{~m}$ commercial solar collector is used to preheat feed water. The collector plate is made of aluminium with $0.9 \mathrm{~mm}$ thickness, and insulated with insulation material of $50 \mathrm{~mm}$ thickness. The collector is parallel tube-type, with seven riser tubes running across the width of collector plate, and connected by two headers.

The desalination chamber used in the study is made of PVC, cylindrical in shape, with a height of 0.5 $\mathrm{m}$ and external diameter of $0.26 \mathrm{~m}$. A condenser is installed at the bottom of the chamber to heat up and evaporate the remaining feed water. It consists of copper coils having length of $12 \mathrm{~m}$, external diameter of $9.5 \mathrm{~mm}$ and thickness of $1 \mathrm{~mm}$. A cooling coil is fixed at the top of chamber. The cooling coil is made with $15 \mathrm{~m}$ length of copper coil, with exact cross-sectional area as the condenser coil.

Three different photovoltaic (PV) panels are installed to supply electrical power to the pumps and blower. The types of PV panel used in the system are Amorphous, mono-crystalline and polycrystalline PV panels.

\subsection{Meteorological model of Singapore}

\section{Mathematical Model And Simulation}

In order to achieve accurate thermal performance of the solar-assisted heat pump system installed at the National University of Singapore, local meteorological data needs to be used. Such meteorological information can be easily obtained from the local meteorological stations. However, daily meteorological data are too large in volume, thus designing a system's simulation based on real time meteorological data is found to be tedious and impractical. To overcome this difficulty, a model to represent the meteorological conditions of Singapore, had been developed by Hawlader et al [12]. This model predicts the average daily values of solar radiation, wind speed, ambient temperature and relative humidity in a certain month:

$$
X=\sum_{n=0}^{7} a_{n} t^{n}
$$

In the above equation, $\mathrm{X}$ represents the hourly values of the parameters (solar radiation, wind speed, ambient temperature and relative humidity), $a_{n}$ represents the coefficient of a polynomial equation, $t$ represents the station time, which is 8 hours ahead of GMT.

\subsection{Modeling of components}

\subsubsection{Evaporator collector}

The evaporator-collector is made of copper with unglazed top surface painted black, copper serpentine tubes are welded to the bottom of the plate for the refrigerant to flow. The energy balancing equation for the 
evaporator collector is given by Hottel and Whillier equation [13]. The useful power gained from the evaporator collector, $\mathrm{Q}_{\mathrm{u}}$ can be expressed as follows:

$$
Q_{u}=F_{R} A_{C}\left[I(\tau \alpha)-U_{L}\left(T_{f}-T_{a}\right)\right]
$$

where, $\mathrm{A}_{\mathrm{C}}$ is the collector area in $\mathrm{m}^{2}, \mathrm{I}$ is the solar radiation in $\mathrm{W} / \mathrm{m}^{2}, \tau \alpha$ is the transmittance-absorptance product, $U_{L}$ is the overall heat transfer coefficient for losses in $W /\left(m^{2} K\right), T_{f}$ and $T_{a}$ are the temperatures of the refrigerant fluid and ambient air respectively. The collector heat removal factor $F_{R}$ is a quantity that relates the actual useful energy gain of a collector to the useful gain if the collector surface is at the fluid inlet temperature and can be expressed as [13]:

$$
F_{R}=\frac{\dot{m}_{f} C p}{A_{C} U_{L}}\left[1-\exp \left(-\frac{A_{C} U_{L} F^{\prime}}{m_{f} C_{P}}\right)\right]
$$

where, $\dot{m}_{f}$ is the refrigerant flow rate in $\mathrm{kg} / \mathrm{s}$ and $\mathrm{Cp}$ is the specific heat capacity in $\mathrm{kJ} / \mathrm{K}$. Collector efficiency factor, $\mathrm{F}^{\prime}$ is defined as the ratio of the heat transfer resistance between collector plate and ambient air to the heat transfer resistance between fluid and ambient air:

$$
F^{\prime}=\frac{\frac{1}{U_{L}}}{W\left[\frac{1}{U_{L}\left\{D_{o}+\left(W-D_{o}\right) F\right\}}+\frac{1}{C_{b}}+\frac{1}{\pi D_{i} h_{f i}}\right]}
$$

where, $D_{o}$ and $D_{i}$ are the outer diameter and inside diameter of the tube respectively and $\mathrm{W}$ is the distance between the centres of 2 adjacent tubes.

The function F, used in Equation (3.4) is defined as the standard fin efficiency, and can be expressed as follows:

$$
F=\frac{2 \tanh \left[\frac{m\left(W-D_{o}\right)}{2}\right]}{m\left(W-D_{o}\right)}
$$

where:

$$
m=\sqrt{\frac{U_{L}}{\kappa \delta}}
$$

$\kappa$ is the thermal conductivity and $\delta$ is the thickness of the collector plate.

Bond conductivity $\mathrm{C}_{\mathrm{b}}$ can be expressed as:

$$
C_{b}=\frac{\kappa_{b} b}{\gamma}
$$

where, $\kappa_{b}$ is the bond thermal conductivity, $b$ is the bond's width and $\gamma$ is the bond's average thickness.

Heat transfer coefficient of the single phase refrigerant vapour can be calculated with Dittus-Boelter equation as follows:

$$
h_{f i}=0.023 \operatorname{Re}^{0.8} \operatorname{Pr}^{0.33} \frac{\kappa_{f}}{D_{i}}
$$

where, $\kappa_{\mathrm{f}}$ is the fluid thermal conductivity, Re and Pr are the Reynolds number and Prandtl number respectively.

\subsubsection{Liquid solar collector}

The solar collector used for preheating the feed water is made of aluminium plating with single glazing. The collector is parallel tube-type, with 7 risers and connected by two headers. In modelling the liquid solar collector, the following assumptions have been made;

1. The collector operates in steady-state conditions.

2. The headers do not affect the thermal performance and efficiency of the collector.

3. There is uniform flow of water in all tubes.

4. Heat transfer is uni-axial, in the direction from glass cover to insulation.

5. Uniform solar radiation throughout the collector plate.

The useful energy absorbed by water, in terms of inlet and outlet temperature of water is expressed as follows:

$$
Q_{u}=\dot{m}_{w} C p_{w}\left(T_{w, o}-T_{w, i}\right)
$$


The overall loss coefficient of solar collector $U_{L}$, heat removal factor $F_{R}$, standard fin efficiency $F$, are determined by the equations discussed in the previous section of evaporator collector. The fluid heat transfer coefficient of single-phase flow of water can be determined by the Dittus-Boelter equation as expressed in Equation (III.8).

\subsubsection{Desalination chamber}

In the desalination chamber, thermodynamic flashing, evaporation and condensation processes occur near simultaneously. Uniform flashing of water takes place when feed water enters the desalination chamber through the spray nozzle, at a temperature higher than the saturation temperature of water.

\subsubsection{Thermodynamic flashing}

Thermodynamic flashing is assumed to have taken place at equilibrium condition. Vapour produced during thermodynamic flashing can be determined using Equation (III.10):

$$
\dot{m}_{v}=\frac{\dot{m}_{\text {feed }} C p_{w}\left(T_{\text {feed }}-T_{w, s a t}\right)}{H_{f g, w}}
$$

$\dot{m}_{\text {feed }}$ and $\mathrm{T}_{\text {feed }}$ are the mass flow rate and temperature of water fed to the desalination chamber respectively. $\mathrm{H}_{\mathrm{fg}, \mathrm{w}}$ is the specific latent heat of water for vaporization and $\mathrm{T}_{\mathrm{w}, \mathrm{sat}}$ is the saturation temperature of water in the desalination chamber.

\subsubsection{Condensing coil}

Useful energy released by the refrigerant can be expressed in terms of the amount of water evaporated as:

$$
Q_{\text {cond }}=\dot{m}_{\text {eva }} H_{f g}
$$

The heat released by the condensing coil can also be written as:

$$
Q_{\text {cond }}=E C_{\min }\left(T_{h, i}-T_{c, i}\right)
$$

where, $T_{h, i}$ is the inlet temperature of hot fluid and $T_{c, i}$ is the inlet temperature of cold fluid. In the present study, $T_{h, i}$ refers to the temperature of superheated refrigerant and $T_{c, i}$ refers to the temperature of saturated feed water. $\mathrm{C}_{\min }$ is the heat capacity of the fluid with the lowest value. In the equation, effectiveness-NTU method is used to determine the effectiveness $\mathrm{E}$ of condensing coil.

\subsubsection{Compressor}

A hermetic-type reciprocating compressor coupled with an electric motor and a frequency inverter is used in the system. The frequency inverter is used to regulate the compressor speed. The compressor model assumes a polytropic compression with a constant polytropic index $n$. Volumetric efficiency of the compressor is expressed as [14]:

$$
\eta_{v}=1+c-c\left(\frac{P_{2}}{P_{1}}\right)^{\frac{1}{n}}
$$

where $\mathrm{c}$ is the clearance volumetric ratio and obtained from the manufacturer's data. $\mathrm{P}_{2}$ and $\mathrm{P}_{1}$ are the outlet and inlet pressures respectively.

If $T_{r, i}$ is the inlet temperature of the refrigerant, the discharge temperature of the refrigerant can be expressed as:

$$
T_{r, o}=T_{r, i}\left(\frac{P_{2}}{P_{1}}\right)^{\frac{n-1}{n}}
$$

\subsubsection{Water cooled condenser}

Using effectiveness-NTU method, heat transferred in terms of maximum temperatures can be expressed as:

$$
Q_{\text {cond }}=E C_{\min }\left(T_{h, i}-T_{c, i}\right)
$$

where, $\mathrm{T}_{\mathrm{h}, \mathrm{i}}$ and $\mathrm{T}_{\mathrm{c}, \mathrm{i}}$ refer to the inlet temperature of refrigerant and water respectively.

\subsubsection{Air cooled condenser and drying chamber}

The drying chamber consists of a simple fan-duct system, incorporated with an air-cooled condenser. A blower draws ambient air into the duct which flows over the finned tube's exterior where heat transfer takes place between air and refrigerant. The heated air is used to dry the wet towels and clothes, after which, the warm moist air is vented to the atmosphere.

Using effectiveness-NTU method, E, $\mathrm{C}_{\min }$ and the amount of transferred heat $\mathrm{Q}_{\text {cond }}$ are determined using the same analogy as used in the case of water cooled condenser (see Section 3.2.5).

Heat absorbed by air can be expressed as: 


$$
Q_{a}=\dot{m}_{a} C p_{a}\left(T_{a, o}-T_{a, i}\right)
$$

And, heat rejected by refrigerant can be expressed as:

$$
Q_{r}=\dot{m}_{r} C p_{r}\left(T_{r, i}-T_{r, o}\right)
$$

\section{Results And Discussion}

Before performing the parametric studies, the prepared model is validated with the experimental data.

\subsection{Validation of simulation model}

\subsubsection{Meteorological Data Validation}

Simulation values of the meteorological conditions were derived from the model developed by Hawlader et. al [12], while actual meteorological readings were recorded on the roof-top of EA block in National University of Singapore. Fig. 4.1, 4.2, and 4.3 show the values of meteorological conditions in Singapore on a single day of January.

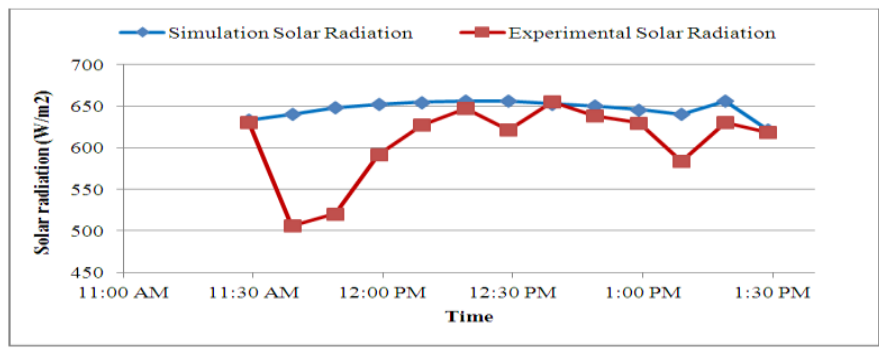

Figure 4.1 Validation of Solar Radiation model

In Fig. 4.1, there are sharp deviations in actual solar radiation from the simulation result; these sharp deviations of result may be accounted by cloud covers, thus limiting the amount of solar radiation reaching the ground. In general, the simulation values of solar radiation correspond with the experimental solar radiation, with solar radiation ranging between 600 to $670 \mathrm{~W} / \mathrm{m}^{2}$.

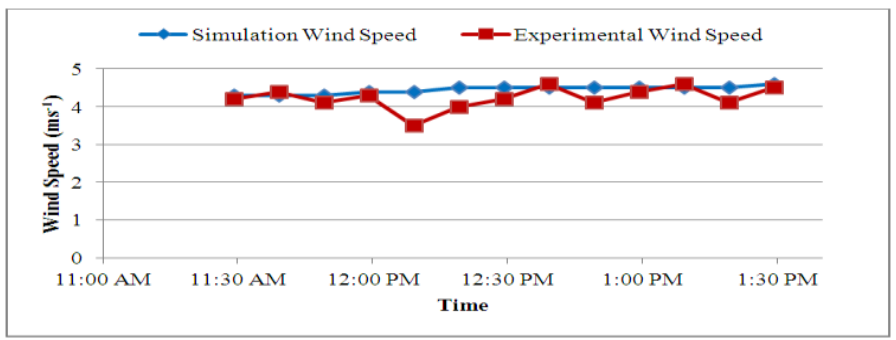

Figure 4.2 Validation of Wind Speed model

In Fig. 4.2, the wind speed in Singapore is in the range of 4 to $4.5 \mathrm{~m} / \mathrm{s}$. From the experimental data recorded, it can be said that the general trend in wind speed is relatively consistent with the wind speed derived from the simulation model.

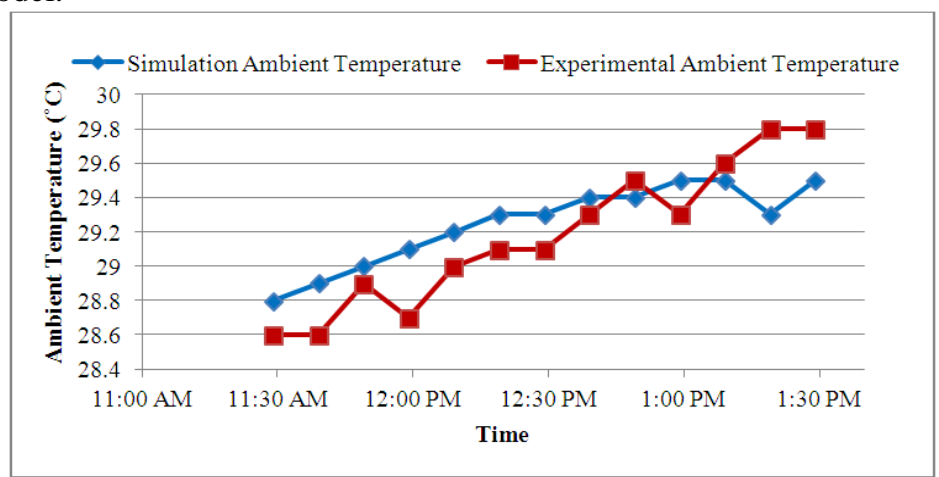

Figure 4.3 Validation of Ambient Temperature model 
In Fig. 4.3, due to solar radiation heating up the surface of the earth, ambient temperature rises in the afternoon. In both simulation results and experimental results, the ambient temperature is within the range of 28 to $30^{\circ} \mathrm{C}$.

Hence, the meteorological model used in this system is validated and found to be relatively accurate in providing meteorological data input for simulation purposes.

\subsubsection{Validation of Desalination Chamber}

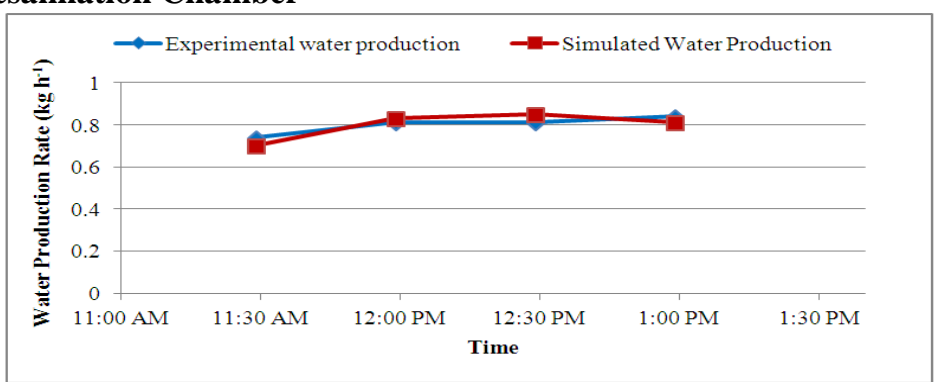

Figure 4.4 Validation of Water Production Rate model

Fig. 4.4 shows the comparison of simulation and experimental results of water production rate against time. The water production rate recorded from the experiment is in the range of 0.7 to $0.85 \mathrm{~kg} / \mathrm{h}$. The simulation values of water production rate are also in the range of 0.7 to $0.85 \mathrm{~kg} / \mathrm{h}$. There is a reduction of water production rate in the simulation results as compared to the experimental values; this is due to a reduction in solar radiation in the simulation. The amount of feed water that undergoes thermodynamic flashing is dependent upon the amount of heat gained at the liquid collector. Therefore, higher solar radiation allows more heat to be gained by the feed water, which increases feed water temperature, giving rise to more water being flashed.

\subsection{Parametric study of system}

The study attempts to look at the different parameters that affect the water production rate. The various parameters included in this study are solar radiation, temperature of feed water at the inlet of the desalination chamber and ambient temperature.

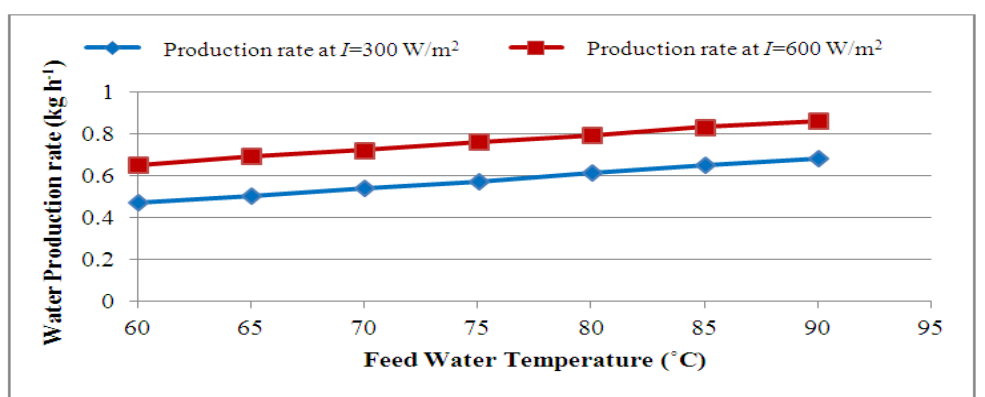

Figure 4.5 Graph of Production rate against temperature

Fig. 4.5 shows the effect of feed water temperature entering the desalination chamber upon the water production rate. Solar radiation is assumed to be constant at $300 \mathrm{~W} / \mathrm{m}^{2}$ and $600 \mathrm{~W} / \mathrm{m}^{2}$ respectively. In Fig. 4.5 , an increase in feed water inlet temperature gives rise to an increase in water production rate. The increase in water production rate at higher feed water inlet temperature is due to the increase in vapour produced during thermodynamic flashing, as expressed in Equation (3.14).

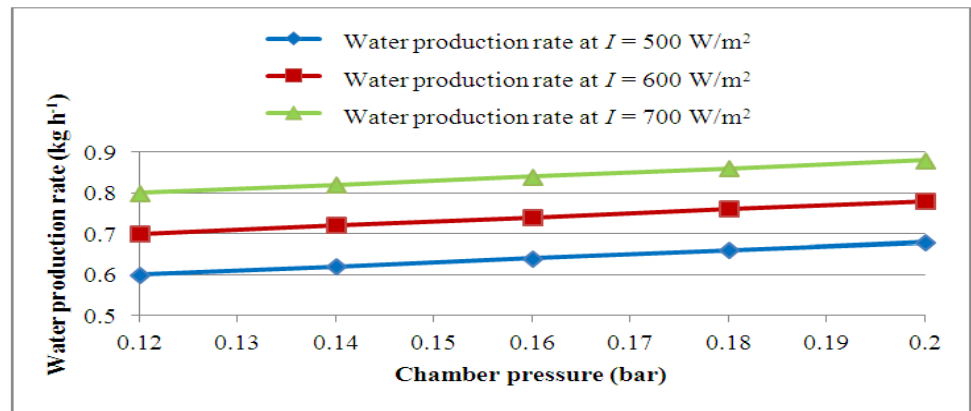

Figure 4.6 Graph of Water production rate against chamber pressure 
Water production rate is also affected by different internal pressure in the desalination chamber. Fig. 4.6 shows the relationship between water production rate and internal pressure of desalination chamber. As the internal pressure of water decreases, water production rate decreases. At higher pressure, the latent heat required to vaporise water decreases, therefore, lesser thermal energy is needed to evaporate water. Furthermore, as shown in Fig. 4.6, production rate with respect to pressure increases with increasing solar radiation. At higher solar radiation, the evaporator collector absorbs more thermal energy, thus delivering more energy into the condenser coil to evaporate the saturated brine water at the bottom of the desalination chamber. Ease of evaporating the feed water, increases vapour production, thereby increases the water production rate of the system.

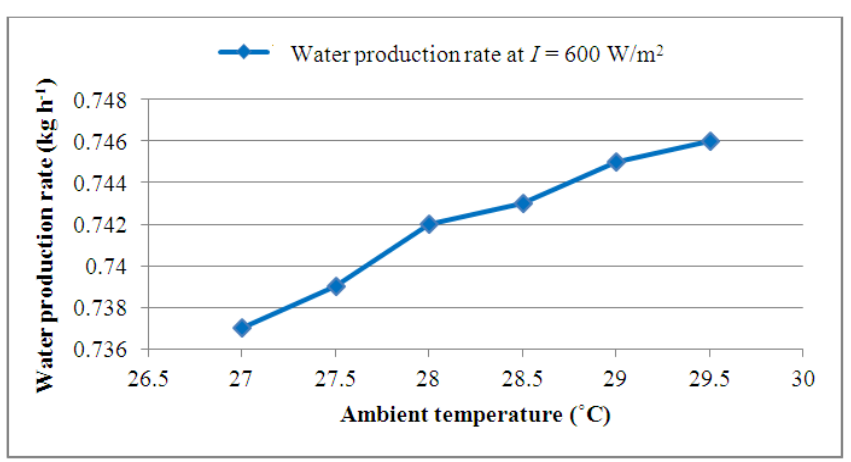

Figure 4.7 Graph of water production rate against ambient temperature

Ambient temperature has less significant impact upon the production rate of water. However, low ambient temperature will result in low efficiency of the collector and reduction in water production rate. Fig. 4.7 shows the relationship between water production rate and ambient temperature. When ambient temperature is low and there is a relatively large temperature difference between the collector plate and ambient air, heat loss at the collector plate increases, resulting in lesser thermal energy transfer to the water and lesser water undergoes flashing.

\section{Conclusions}

Due to the interest in green energy for thermal application, an integrated solar assisted heat pump system for water desalination, water heating and drying has been designed and studied. The mathematical model of the system and a simulation program based on MATLAB programming language has been developed for simulation purposes and performance analysis of the system. The comparison of simulation results with experimental results shows good agreement with each other; it indicates that the simulation program would be a reliable agent for predicting the performance of the system under the given meteorological condition of the local region. The simulation program has also been used for carrying out parametric studies on the system. The parametric study provides further analysis on the various factors that can affect the performances of the system.

The parametric study shows that the water production rate increases with respect to solar radiation and feed water temperature. Meanwhile, feed water temperature also increases with respect to higher solar radiation. However, higher solar radiation values result in lower efficiency of the evaporator collector and liquid solar collector. Higher solar radiation results in higher thermal energy gained by the working fluid, thus resulting in greater heat loss to the ambient surrounding. On the contrary, lower ambient temperatures result in a slight drop in water production rate of the system.

In conclusion, solar-assisted heat pump system has great potential in harnessing green energy sources from solar energy, waste heat and ambient energy for water desalination. This system is designed to operate in the industrial and domestic sector in the future. In order to achieve more accurate results, the desalination system should be tested at larger scale, so as to increase production capacity, to meet the industrial demand.

In the current system, single-effect desalination is currently designed for the desalination system. However, to further utilize the thermal energy of refrigerant leaving the condenser coil, additional desalination chambers can be built for further desalination of the brine water. Such implementation increases water production rate, thereby increases system productivity. 


\section{References}

[1] Quarmby, Ian, Structural Adhesive: A bonding alternative for Solar panels. ElectroIQ. The Portal for Electronic Manufacturing. [Online] March 23, 2010. [Cited: march 29, 2010.] http://www.electroiq.com/index/display/photovoltaics-articledisplay/5066567015/articles/Photovoltaics-World/bos-components/module-assembly/2010/march/structural-adhesives.html.

[2] Water.org. Water.org. [Online] October 22, 2009. [Cited: January 16, 2010.] http://water.org/learn-about-the-water-crisis/facts/.

[3] Water for Life. United Nation Water. [Online] $2006 . \quad$ [Cited: December 3, 2009.] http://www.un.org/waterforlifedecade/background.html.

[4] Gleick, Peter H.,The Biennial Report on Freshwater Resources, The World's Water, p. xi., 2009.

[5] Khawaji, Akili D and Ibrahim K. Kutubkhanah, Jong-Mihn Wie., Advances in seawater desalination technologies, Desalination, 2008, 47-69.

[6] Ozgener, Onder and Hepbasli, Arif., A review on the energy and exergy analysis of solar assisted heat pump systems., Renewable \& Sustainable Energy Reviews, 2007, 482-496.

[7] Hawlader M.N.A., Jahangeer K.A., Solar heat pump drying and water heating in the tropics, Solar Energy, 2006, 429-499.

[8] Huang, Chyng, Performance characteristics of integral type solar assisted heat pump, Solar Energy, 2001, 403-414

[9] Best R., Cruz J.M., Gutierrez J., Soto W., Experimental Results of a solar assisted heat pump rice drying system, World Renewable Energy Congress Renewable Energy, Energy Efficiency and the Environment, 1996, 690-693.

[10] Chaturvedi S.K., Abdel-Salam T.M., Sreedharan S.S., Gorozabel F.B., Two-stage direct expansion solar-assisted heat pump for high temperature applications, Applied Thermal Energy.,2009

[11] Yumrutas. R, Kunduz M, Ayhan T., Investigation of thermal performance of a ground coupled heat pump system witha cylindrical energy storage tank, Energy Resource, 2003, 1051-1066.

[12] Hawlader M.N.A., Bong T.Y., Mahmood W., A method of estimating monthky global radiation for Singapore, International Journal of Solar Energy, 1988, 279-288.

[13] Duffie, John A., Willian A. Beckman, Solar Engineering of Thermal Processes, 1980.

[14] Brown, Royce N., Compressors: Selection and Sizing, Elsevier, 2005. 